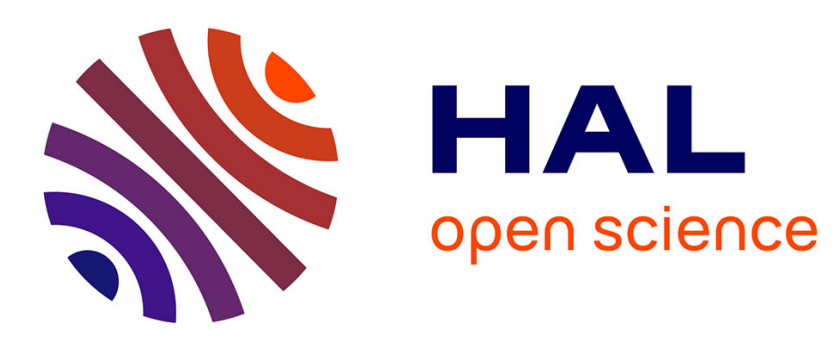

\title{
Mesoporous Carbon Design for Ionic Liquid-Based, Double-Layer Supercapacitors
}

\author{
Mariachiara Lazzari, Francesca Soavi, Marina Mastragostino
}

\section{To cite this version:}

Mariachiara Lazzari, Francesca Soavi, Marina Mastragostino. Mesoporous Carbon Design for Ionic Liquid-Based, Double-Layer Supercapacitors. Fuel Cells, 2010, 10 (5), pp.840. 10.1002/fuce.200900198 . hal-00555613

\section{HAL Id: hal-00555613 https://hal.science/hal-00555613}

Submitted on 14 Jan 2011

HAL is a multi-disciplinary open access archive for the deposit and dissemination of scientific research documents, whether they are published or not. The documents may come from teaching and research institutions in France or abroad, or from public or private research centers.
L'archive ouverte pluridisciplinaire HAL, est destinée au dépôt et à la diffusion de documents scientifiques de niveau recherche, publiés ou non, émanant des établissements d'enseignement et de recherche français ou étrangers, des laboratoires publics ou privés. 


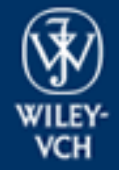

Fuel Cells

VCH

\section{Mesoporous Carbon Design for Ionic Liquid-Based, Double- Layer Supercapacitors}

\begin{tabular}{|r|l|}
\hline Journal: & Fuel Cells \\
\hline Manuscript ID: & fuce.200900198.R1 \\
\hline Wiley - Manuscript type: & Original Research Paper \\
\hline Date Submitted by the \\
Author: & $10-$ May-2010 \\
\hline Complete List of Authors: & $\begin{array}{l}\text { Lazzari, Mariachiara; University of Bologna, Dipartimento di Scienza } \\
\text { dei Metalli, Elettrochimica e Tecniche Chimiche } \\
\text { Soavi, Francesca; University of Bologna, Dipartimento di Scienza } \\
\text { dei Metalli, Elettrochimica e Tecniche Chimiche } \\
\text { Mastragostino, Marina; University of Bologna, Dipartimento di } \\
\text { Scienza dei Metalli, Elettrochimica e Tecniche Chimiche }\end{array}$ \\
\hline Keywords: & $\begin{array}{l}\text { Electrochemical Power Sources, Electrode, AC-Impedance } \\
\text { Spectroscopy, Cyclic Voltammetry, Time Constant, Vehicle } \\
\text { Application }\end{array}$ \\
\hline
\end{tabular}




\title{
Mesoporous Carbon Design for Ionic Liquid-Based, Double-Layer Supercapacitors
}

\author{
M. Lazzari ${ }^{1}$, F. Soavi ${ }^{1}$, Marina Mastragostino ${ }^{1}$ \\ ${ }^{1}$ Dipartimento di Scienza dei Metalli, Elettrochimica e Tecniche Chimiche, University of Bologna, Via San \\ Donato 15, 40127 Bologna, Italy
}

[*] Corresponding Author, francesca.soavi@unibo.it

\begin{abstract}
The use of pyrrolidinium-based ionic liquids (ILs) in asymmetric electric double-layer capacitors (AEDLC) with positive and negative carbon electrodes of different weight is a powerful strategy for developing safe, high specific-energy supercapacitors operating at $>3.5 \mathrm{~V}$. The preparation and characterization of ordered (OTC) and disordered (DTC) template carbons, the latter obtained by a fast and low-cost method, are reported. The porosity and capacitance features of the template carbons are discussed in view of their application in IL-based AEDLCs and compared with the properties of aero/cryo/xerogel carbons and a commercial activated carbon. The performance of an N-butyl-N-methyl pyrrolidinium bis(trifluoromethanesulfonyl)imide-based AEDLC assembled with DTC carbon electrodes operating at $3.9 \mathrm{~V}$ featuring high specific energy of $47 \mathrm{Wh} \mathrm{kg}^{-1}$ is then reported. The impact of porosity and surface chemistry of carbons on the electrode capacitive response in IL and on the performance of the IL-based AEDLC in terms of energy, power and weight distribution of module components is discussed. The effect of IL nature and carbon porosity on the time constant of the double-layer charging process was also investigated by voltammetric and impedance studies.
\end{abstract}

Keywords: Mesoporous Carbons, Ionic Liquids, Supercapacitors, Time Constant, Impedance, Capacitance.

\section{Introduction}

Ionic liquids (IL) are key materials in the research and development of supercapacitors. Their high thermal, chemical and electrochemical stability and good conductivity above room temperature are exploitable for the development of high-voltage, solvent-free supercapacitors that are intrinsically safer and with higher specific energy than those already on the market based on conventional organic electrolytes. The chemical physical properties of Its strongly depend on cation and anion chemistries. While imidazolium salts like 1-ethyl-3methylimidazolium bis(trifluoromethanesulfonyl)imide (EMITFSI) typically exhibit the highest ionic conductivities, pyrrolidinium based ones like $\mathrm{N}$ butyl $\mathrm{N}$-methyl pyrrolidinium bis(trifluoromethanesulfonyl)imide (PYR ${ }_{14}$ TFSI) and $\mathrm{N}$ - methoxyethyl- $\mathrm{N}$ methylpyrrolidinium bis (trifluoromethanesulfonyl)imide (PYR (2O1) $_{12}$ TFSI) feature the widest electrochemical stability. The IL aptitude to oxidation and reduction marks the electrochemical stability window (ESW) that may differ depending on the nature of the electrode used for the latter evaluation. Pyrrolidinium salts typically exhibit the widest ESWs, wider even than $5 \mathrm{~V}$ when evaluated by glassy carbon electrodes and that narrows to $4.2 \mathrm{~V}$ when measured by high-surface area carbons. One of the best candidates for supercapacitor applications is $\mathrm{N}$-methoxyethyl-N methylpyrrolidinium bis(trifluoromethanesulfonyl)imide $\left(\mathrm{PYR}_{1(2 \mathrm{Ol})} \mathrm{TFSI}\right)$ because it freezes below $-90^{\circ} \mathrm{C}$ and features conductivities of $1 \cdot 10^{-4}-1 \cdot 10^{-2} \mathrm{~S} \mathrm{~cm}^{-1}$ in the wide temperature range between $-30^{\circ} \mathrm{C}$ and $60^{\circ} \mathrm{C}[1-3]$.

The use of pyrrolidinium-based ILs in asymmetric electric double-layer capacitors (AEDLC) with positive and negative carbon electrodes of different weight is a powerful strategy for the development of safe, highspecific energy supercapacitors operating at $>3.5 \mathrm{~V}$. The wide ESW of these ILs is exploited by the asymmetric configuration of the AEDLCs, which are assembled with electrodes of different carbon loading. This strategy has already been pursued with success in AEDLCs based on both treated commercial activated carbons and xerogel carbons; these supercapacitors, when tested with maximum cell voltage up to $4.0 \mathrm{~V}$, displayed capacitance of ca. $20-25 \mathrm{~F} \mathrm{~g}^{-1}$ (only electrode weight is considered), which is competitive with that of commercial symmetric electric electrochemical double-layer capacitors (EDLCs) with conventional organic electrolyte and operating at 2.7 V maximum [4-7].

Further improvements in IL-based AEDLCs are expected from the use of novel carbon electrodes that have increased capacitance and low time constant $(\tau)$ of the double-layer charging process, conditions which are closely related to the intrinsic properties of IL and the carbons.

The capacitance response of carbon electrodes in IL $\left(\mathrm{C}_{\mathrm{dl}}\right)$ is given by terms as in eq. (1) $\mathrm{E}_{\mathrm{dt}}^{-1}=\mathrm{C}_{\mathrm{e}}^{-1}+\mathrm{C}_{\mathrm{H}}^{-4}$

where $C_{\mathrm{e}}$ and $\mathrm{C}_{\sharp}$ are the capacitances originated by the space charge layer inside the carbon $\left(\mathrm{C}_{\mathrm{c}}\right)$ and by the packing of ions inside the IL electrolyte $\left(\mathrm{C}_{\mathrm{IL}}\right)$, respectively $[8,9]$. The design of carbons for IL-based AEDLC should thus consider the electronic properties of the carbon and the intimate contact, not mediated by solvent, between the carbon surface and IL. In solvent-free IL the electrified electrode surface is set up against the IL 
counterions located in the inner Helmholtz plane of the double-layer. This implies that IL chemistry, carbon/IL interface structure, and surface chemistry and porosity of the carbon are crucial for the capacitive response of the carbon electrode in IL. Ion size, orientation under electric field and polarizability of IL ions directly affect thickness and the dielectric constant of the double-layer [9-12].

At equal IL, high capacitance at high charge/discharge rate is achieved by electrode materials featuring a high surface area that is easily accessed by the IL. Surface functionality should be tailored to enhance carbon wettability with IL, and, in the case of hydrophobic ILs with the TFSI ${ }^{-}$anion, the hydrophilic acidic groups on the carbon surface should be avoided [12].

The surface area should be mainly originated by pores with walls thick enough $(c a .>1 \mathrm{~nm})$ so as not to limit charge accommodation in the solid part of the interface and that are sufficiently wide in order to let the whole area be coated at least by an IL monolayer, which avoids charge limitation on the electrolyte side. High surface area is achieved by high pore volume, which should be constrained under certain limits not only to avoid thin pore walls and low $\mathrm{C}_{\mathrm{c}}$ but also to prevent excess electrolyte in the electrodes that negatively impacts on the whole supercapacitor weight and, hence, on its specific energy and power. Unlike in conventional electrolyte solutions, the pores in solvent-free ILs are already filled with the ions almost at the maximum concentration, and the double-layer charging process should only involve a redistribution of charges within the pores. The charge of pores smaller than $1.5 \mathrm{~nm}$ would be hindered because of the relatively large size of the ionic liquid ions, which typically feature sizes of $0.6-0.7 \mathrm{~nm}$, and would at least require distortion of ions or even involve insertion processes [3, 13-16]. If we assume a cylindrical shape of the pores, only pores wider than 2-3 nm would guarantee the formation of an IL monolayer on the cylinder's whole inner surface, and, thus, be fully and easily exploited for the double-layer capacitance. Thus, if we take into account carbons featuring capacitances of ca. $100 \mathrm{~F} \mathrm{~g}^{-1}$, electrode potential excursions at least of $2 \mathrm{~V}$, and typical IL formula weight of 300-400 $\mathrm{g} \mathrm{mol}^{-1}$ and IL density of $1.3-1.4 \mathrm{~g} \mathrm{~cm}^{-3}$, the optimal carbon pore volume, which would be filled with IL, should be $0.5-0.6 \mathrm{~cm}^{3}$ $\mathrm{g}^{-1}$ from $2-3 \mathrm{~nm}$ wide pores.

Different approaches can be pursued to synthesize mesoporous carbons [17, 18]. In the case of aero/cryo/xerogel carbons (ACX), the porosity is tuned by modifying the crosslinking degree of the organic gel precursor and by modulating thickness and length of the polymer that, once dried and pyrolized, yields the carbonaceous matrix. The mesopore volume increases with gel dilution, which also increases pore size, so that there is no marked gain in specific surface area. Only by activation is it possible to achieve a specific surface area higher than $500 \mathrm{~m}^{2} \mathrm{~g}^{-1}$ from pores $>1.5 \mathrm{~nm}\left(\mathrm{~S}_{>1.5 \mathrm{~nm}}\right)$ higher than $500 \mathrm{~m}^{2} \mathrm{~g}^{-1}$ [6].

The template syntheses of mesoporous carbons allow a good control of the porosity of carbons because the amount of template is accurately set with respect to that of the carbon precursors, so that, after pyrolysis and template removal, it is possible to obtain certain pore volume/carbon ratios while keeping the same pore size distribution, which in turn depends only on template size. The geometry of the templating agent is replicated in the pores and affects the specific surface of the carbon [17-25].

In order to achieve high capacitance response at controlled pore volume, we synthesized and tested ordered (OTC) and disordered (DTC) template mesoporous carbons, the latter obtained by a fast and low-cost method. The porosity and capacitance features of the template carbons are discussed in view of their application in ILbased AEDLCs and compared with the properties of ACX carbons and a commercial activated carbon. The performance of a $3.9 \mathrm{~V}$ PYR ${ }_{14}$ TFSI-based AEDLC assembled with N-butyl-N-methyl pyrrolidinium bis(trifluoromethanesulfonyl)imide $\left(\mathrm{PYR}_{14} \mathrm{TFSI}\right) \mathrm{IL}$ and disordered template carbon electrodes is reported and the role of IL nature and carbon porosity on the time constant $(\tau)$ of the charge-discharge process evaluated by voltammetric and impedance studies is discussed.

\section{Experimental \\ 2.1 Carbons}

The ordered mesoporous OTC carbon was prepared using the hexagonal SBA15 template silica synthesized as per refs. [20-22] by tetraethyl orthosilicate (TEOS, $>99 \%$ Fluka) and Pluronic P123 (Aldrich, $\mathrm{M}_{\mathrm{w}}=5800$ ) solution in $\mathrm{HCl}$, aged at $90^{\circ} \mathrm{C}$ and calcinated at $600^{\circ} \mathrm{C}$ for $8 \mathrm{~h}\left(2^{\circ} \mathrm{C} \mathrm{min}{ }^{-1}\right)$. The SBA15 silica framework featured a pore volume of $0.9 \mathrm{~cm}^{3} \mathrm{~g}^{-1}$, pores of $7 \mathrm{~nm}$ with walls of $3 \mathrm{~nm}$, as evaluated by nitrogen adsorption porosimetry and X-ray diffraction (XRD) measurements in agreement with ref. [20]. The OTC carbon was prepared by incipient wetting of the SBA15 template with phenanthrene (98\% Aldrich)/p-toluensulphonic acid monohydrate $(98.5 \%$ Fluka) in 1/3.12 molar ratio in acetone using a phenanthrene mass/SBA15 pore volume ratio of $0.55 \mathrm{~g}$ $\mathrm{cm}^{-3}$. Pyrolysis was performed at $900^{\circ} \mathrm{C}$ for $1 \mathrm{~h}$ with heating rate of $5^{\circ} \mathrm{C} / \mathrm{min}$ in $\mathrm{Ar}\left(200 \mathrm{cc} \mathrm{min}^{-1}\right)$; the SBA15 template was removed with a hydro-alcoholic solution of $\mathrm{NaOH}$.

The earbon DTC carbon was prepared from Mg citrate ( $>98 \%$ Fluka) and polystyrene (pellets, Aldrich $\mathrm{M}_{\mathrm{w}}=$ 192000) after the procedure in refs. [23-25]. The polystyrene was grounded by universal mill M20 (IKA) and then mixed to magnesium citrate in the weight ratio 1:5 by ball milling using planetary mill (Pulverisette) in agate jar. The mixture was pyrolysed at $900^{\circ} \mathrm{C}$ for $1 \mathrm{~h}$ with heating rate of $5^{\circ} \mathrm{C} \mathrm{min}-1$ in $\mathrm{Ar}\left(200 \mathrm{cc} \mathrm{min}{ }^{-1}\right)$. The 
resulting powder was milled at $400 \mathrm{rpm}$ and for $1 \mathrm{~h}$ and then washed with $\mathrm{H}_{2} \mathrm{SO}_{4} 2 \mathrm{M}$ to dissolve $\mathrm{MgO}$ template, which was formed upon pyrolysis with crystallite size of $4 \mathrm{~nm}$, as evaluated by XRD.

\subsection{Porosity analysis}

Nitrogen adsorption porosimetry measurements were carried out at $77 \mathrm{~K}$ with an ASAP 2020 system (Micromeritics); the carbon powders were dried for at least $2 \mathrm{~h}$ at $120^{\circ} \mathrm{C}$ before testing. The $\mathrm{N}_{2}$ adsorption isotherms were analyzed by Density Functional Theory (DFT) and the specific surface area related to pores wider than $1.5 \mathrm{~nm}\left(\mathrm{~S}_{>1.5 \mathrm{~nm}}\right)$ was evaluated by DFT mesoporous volume (from pores with size between $1.5 \mathrm{~nm}$ and $200 \mathrm{~nm}, \mathrm{~V}_{>1.5 \mathrm{~nm}}$ ) by assuming a cylindrical pore geometry except where indicated otherwise.

\subsection{Electrochemical tests}

The carbon electrodes $\left(0.6-0.7 \mathrm{~cm}^{2}\right.$ geometric area, $7-10 \mathrm{mg} \mathrm{cm} \mathrm{c}^{-2}$ carbon loading) were prepared by mixing 95\% w/w carbon and 5\% w/w polytetrafluoroethylene binder (pTFE, Du-Pont) or 90\% carbon, 5\% SuperP (Erachem) carbon conducting additive, 5\% pTFE in ethanol. The suspension was evaporated to yield a film that was then laminated on carbon coated aluminum grids (Lamart Corp.).

The PYR ${ }_{14}$ TFSI (Solvent Innovation, 98\%) and 1-ethyl-3-methylimidazolium bis(trifluoromethanesulfonyl)imide (EMITFSI, Solvent Innovation, 99\%) ILs were dried over night at $80^{\circ} \mathrm{C}$ under dynamic vacuum (Büchi Glass Oven B-580) and displayed ca 30 ppm of water as checked by Karl Fisher titration (684 KF Coulometer Metrohm). PYR 1(2O1) TFSI (Evonik Industries) was used as received and featured a water content lower than $20 \mathrm{ppm}$.

The electrochemical tests were carried with Swagelok-type, "three-electrode" cells assembled in dry box (MBraun Labmaster 130, $\mathrm{H}_{2} \mathrm{O}$ and $\mathrm{O}_{2}<1 \mathrm{ppm}$ ). Silver disk was used as quasi-reference electrode for the cyclic voltammetries $(\mathrm{CV})$ and to check electrode potentials during supercapacitor galvanostatic cycling (GC) . Silver disk potential, which was measured in conventional cells prior to the electrochemical tests by adding the highly reversible redox couple ferrocene/ferrocinium ( $\mathrm{Fc} / \mathrm{Fe}^{+}$) to the medium, was $(-0.20 \pm 0.01) \mathrm{V} v s$. ferrocene/ferrocinium $\left(\mathrm{Fc} / \mathrm{Fc}^{+}\right)$; hereinafter the electrode potentials are given $v s$. $\mathrm{Fc} / \mathrm{Fc}^{+}$for comparison with literature. The cells were assembled by sandwiching two carbon composite electrodes either side of a fiber glass separator (Durieux, $200 \mu \mathrm{m}$ thick when pressed); for single-electrode studies, double-layer carbon counterelectrodes with charge storage capability significantly higher than that of the working electrodes were used so as not to limit the capacitive response of the working electrode. The cells were kept at a controlled temperature of $30^{\circ} \mathrm{C}$ or $60^{\circ} \mathrm{C}$ using a Thermoblock (FALC). The CVs and GCs were performed with a Perkin-Elmer VMP multichannel potentiostat/galvanostat. The specific capacitance was evaluated by CV from the slope of the integral over time of the discharge voltammetric current vs. electrode potential plot.

The impedance spectroscopy measurements were performed by a Solartron SI 1255 frequency-response analyzer coupled to a 273A PAR potentiostat/galvanostat. Impedance spectra were recorded at DC $-1.2 \mathrm{~V}$ vs. $\mathrm{Fc} / \mathrm{Fc}^{+}$with $5 \mathrm{mV}$ AC perturbation in the $100 \mathrm{kHz}$ to $10 \mathrm{mHz}$ frequency range.

\section{Results and Discussion}

We obtained the OTC carbon using the common ordered template SBA15, a mesostructured silica with hexagonally ordered cylindrical nanochannels, and phenanthrene/p-toluensulphonic acid solution as carbon precursor. Removal of the template after carbon pyrolysis leaves the imprint of the hexagonal framework and pores having a width at least equal to the thickness of the silica branches [19-22]. The earben-DTC carbon was synthesized by the formation of the disordered templating agent $\mathrm{MgO}$ in situ upon pyrolysis of $\mathrm{Mg}$ citrate, which is also the carbon precursor, and polystyrene, which prevents agglomeration of $\mathrm{MgO}$ in the early stages of carbonization. The $\mathrm{MgO}$ dissolution creates pores in the carbon matrix that replicate the size of the oxide crystallites [23-25]. Table 1 summarizes the porosity features of the template carbons we synthesized and of other mesoporous carbons we investigated for IL-based AEDLC [5, 6, 12], i.e. a series of aero/cryo/xerogel (ACX) carbons and a commercial activated carbon both pristine (AC) and with a surface cleaned by heat treatment (ACT).

The OTC and DTC carbons displayed narrow pore size distributions (PSDs) centred at $5.7 \mathrm{~nm}$ and $2.7 \mathrm{~nm}$, respectively, values wide enough to provide IL ions with easy access to the carbon surface as shown in Figure 1, which reports the PSDs of the two template carbons as well as that of the ACT and of the meso-macroporous cryogel C3 carbons for comparison.

While the pore shape in DTC reproduces that of the almost spherical $\mathrm{MgO}$ crystals that are randomly distributed in the carbon matrix [23-25], the pores of OTC replicate the silica network and are slit-shaped [19-22]. Thus, the relation between volume and surface is different in the two cases and a smaller gain in surface area is achieved in the latter carbon. Even in the case of the ACX carbons the mesopores are typically cylindrical in shape, so that the former feature higher surface area than the OTC when the same pore width and volume are considered as in the case of the X1a e A1a carbons.

The various $S_{>1.5 \mathrm{~nm}}$ values of the carbons reported in Table 1 bring about different $\mathrm{C}_{\mathrm{dl}}$ capacitive responses $\left(\mathrm{C}_{\mathrm{dt}}\right)$. Figure 2 reports the $\mathrm{C}_{\mathrm{dl}}$ values at $60^{\circ} \mathrm{C}$ in PYR ${ }_{14}$ TFSI vs. $\mathrm{S}_{>1.5 \mathrm{~nm}}$ of all the mesoporous carbons we investigated for IL-based AEDLCs. The capacitive response of the OTC carbon is $60 \mathrm{~F} \mathrm{~g}^{-1}$ and, when normalized to $S_{>1.5 \mathrm{~nm}}$, becomes ca. $20 \mu \mathrm{F} \mathrm{cm}{ }^{-2}$, i.e. almost the same as that of the ACX series. 
The DTC specific capacitance of $140 \mathrm{~F} \mathrm{~g}^{-1}$ is the highest we have obtained up to now in PYR ${ }_{14}$ TFSI. However, it is lower than expected on the basis of the trend with $S_{>1.5 \mathrm{~nm}}$ observed with the OTC and ACX carbons. This may be explained by a non-optimized ionic connection between the disordered pores or by a $\mathrm{C}_{\mathrm{dl}}$ capacitance limitation at the electrode/IL interface due to a low $\mathrm{C}_{\mathrm{c}}$ space charge capacitance in the carbon (see eq. 1) [8,9]. Indeed, on the basis of geometric considerations, the DTC carbon pore walls have an average thickness in the order of few graphene layers that is close to the screening length of the electric field in the carbon. Thinner walls can be estimated for the AC and ACT carbons, which exhibit significantly lower $\mathrm{C}_{\mathrm{dl}}$ than DTC's at the same d value but higher pore volume and larger PSD (see Figures 1 and 2 and Table 1). Note that the higher capacitance of ACT with respect to AC is due to the surface cleaning by heat treatment in inert atmosphere, which significantly improves hydrophobic IL uptake on the carbon surface by removing hydrophilic moieties that are typically present in commercial activated carbons [12].

DTC features a notably high capacitive response, a synthesis procedure that is cheaper and faster than both the aero/cryo/xerogel method and those based on ordered templates, and a moderate mesopore volume which should limit IL excess in the electrode. Given these features, the DTC carbon was used in PYR ${ }_{14}$ TFSI-based AEDLC assembled with positive to negative electrode loading ratio $\left(\mathrm{R}_{+/-}\right)$of 1.3 and total composite electrode mass ( $\mathrm{w}_{\text {comp }}$ ) of ca. $20 \mathrm{mg} \mathrm{cm}^{-2}$. Figure 3 reports the cell voltage profile upon the $1100^{\text {th }}$ charge-discharge galvanostatic cycle of the supercapacitor at $20 \mathrm{~mA} \mathrm{~cm}^{-2}$ and $60^{\circ} \mathrm{C}$ with maximum cell voltage $\left(\mathrm{V}_{\max }\right) \mathrm{of} 3.9 \mathrm{~V}$. Table 2 reports the specific capacitance $(C)$, equivalent series resistance (ESR), discharge capacity (Q), coulombic efficiency $(\eta)$, maximum specific energy and power as evaluated by the analysis of the profile shown in Figure 3. The high capacitance and cell voltage of this PYR 14 TFSI based AEDLC results in an exceptionally high specific energy value, i.e. it The specific energy of this PYR ${ }_{14}$ TFSI-based AEDLC is $25-35 \%$ higher than that published up to now and obtained with ACT and X3a carbons and IL electrolyte [5,6]. The ionic liquid volume required to balance the $\mathrm{Q}$ charge reported in Table 2 is ca. $0.5 \mathrm{~cm}^{3}$ per gram of carbon and lower than the $\mathrm{V}_{>1.5 \mathrm{~nm}}$ pore volume of the DTC carbon $\left(0.70 \mathrm{~cm}^{3} \mathrm{~g}^{-1}\right)$. It is a volume that avoids electrolyte starving, at least in the cycling conditions we adopted, and makes it possible to achieve a composite electrode-to-electrolyte loading ratio of ca. 1 , so that the complete supercapacitor module might weigh 2.5 or 3 times $\mathrm{w}_{\text {comp }}$ depending on the contribution of current collectors, separator and case to total mass.

Specific energy and power values related to complete cell weight of $16-18 \mathrm{Wh} \mathrm{kg}^{-1}$ and $4-5 \mathrm{~kW} \mathrm{~kg}^{-1}$ are thus feasible. These are very interesting results and indicate that the use of the DTC carbon in PYR ${ }_{14}$ TFSI-based AEDLC makes it possible to triple-significantly exceed the energy of the best performing EDLCs on the market operating with propylene carbonate- or acetonitrile-based electrolytes. However, the increase in power is not as marked as expected on the basis of the high operating voltage of the cell. In effect, the ESR does not seem to be competitive with that of conventional EDLC with organic electrolytes and also implies that the time constant $(\tau)$ for the charge-discharge process of the IL-based system is higher than that of the commercial ones. For example, $1.2 \mathrm{kF}-\mathrm{PYR}_{14}$ TFSI-based AEDLC with DTC electrodes and $\mathrm{w}_{\text {comp }}$ of $20 \mathrm{mg} \mathrm{cm}^{-2}$ would feature an ESR of $7 \mathrm{~m} \Omega$ and $\tau$ of $c a .8 \mathrm{~s}$, which are 8 times higher than those of a $1.2 \mathrm{kF}$ Panasonic ultracapacitor operating with propylene carbonate - tetraethyl ammonium tetrafluoroborate, although this ultracapacitor features only $\mathrm{V}_{\max }$ of $2.5 \mathrm{~V}, \mathrm{E}_{\max }=2.3 \mathrm{Wh} \mathrm{kg}^{-1}$ at almost the same $\mathrm{P}_{\max }$ of $4.6 \mathrm{~kW} \mathrm{~kg}^{-1}$ [7].

In order to investigate what mainly affects ESR and $\tau$ of IL-based AEDLCs, we performed voltammetric and impedance studies of carbon electrodes in various ILs and at various temperatures. Table 3 shows the normalized capacitance $\left(\% \mathrm{C}_{\mathrm{dl}} / \mathrm{C}_{\mathrm{dl} \text {,max }}\right)$, i.e. the electrode capacitance $\left(\mathrm{C}_{\mathrm{dl}}\right)$ divided by the maximum value exhibited at the lowest scan rate $\left(\mathrm{C}_{\mathrm{dl}, \max }\right)$, at different voltammetric scan rates of DTC electrodes in $\mathrm{PYR}_{14}$ TFSI and $\mathrm{PYR}_{1(2 \mathrm{O})} \mathrm{TFSI}$ at $30^{\circ} \mathrm{C}$ and $60^{\circ} \mathrm{C}$ and in the negative potential domain; the data for electrodes featuring $5 \%$ of carbon conducting additive (SuperP) are also reported. The $\% \mathrm{C}_{\mathrm{dl}} / \mathrm{C}_{\mathrm{dl} \text {, max }} v s$ scan rate trend is representative of the rate capability of the electrode, i.e. of the time constant of the charge-discharge process, and it should be affected by electrolyte and electrode resistances. In both the ILs and at each temperature, the $\% \mathrm{C}_{\mathrm{dl}} / \mathrm{C}_{\mathrm{dl} \text {,max }}$ values reported in Table 3 decrease as the scan rate increases, i.e. with the voltammetric charge-discharge current increase. This is a typical response of porous carbon electrodes and has already been observed with conventional organic electrolytes and explained by ionic diffusion limitation upon the double-layer charge-discharge of the electrodes' smallest pores [26]. However, what we see in Table 3 is that the $\% \mathrm{C}_{\mathrm{dl}} / \mathrm{C}_{\mathrm{dl} \text {, max }}$ vs. scan rate trend is not much

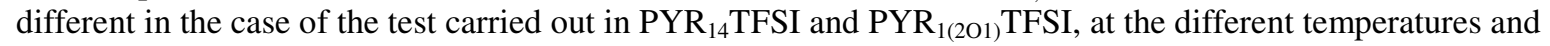
with or without electronically conducting additive in the carbon electrode. This suggests that the time constant for the double-layer charging process is not much affected by the bulk ionic conductivity of the electrolytes, of 6.0 and $8.4 \mathrm{mS} \mathrm{cm}^{-1}$ at $60^{\circ} \mathrm{C}$ and 2.6 and $3.8 \mathrm{mS} \mathrm{cm}^{-1}$ at $30^{\circ} \mathrm{C}$ for PYR ${ }_{14}$ TFSI and $\mathrm{PYR}_{1(2 \mathrm{O})}$ TFSI, respectively, and by the electronic conductivity of the electrodes. On the other hand, $\tau$ is influenced by $\mathrm{C}_{\mathrm{d}}$, which increases in IL along with the latter's conductivity and temperature; this is an inherent characteristic of the electrochemical response of electrodes in ILs, where the capacitive response is affected by IL ion association and polarizability [9-11]. Indeed, as an example, the specific capacitance of DTC in PYR ${ }_{14}$ TFSI at $20 \mathrm{mV} \mathrm{s}^{-1}$ and $60^{\circ} \mathrm{C}$ is $10 \%$ higher than at $30^{\circ} \mathrm{C}$.

The rate capability of the carbon electrodes in IL was further investigated by impedance spectroscopy measurements and Figures 4-6 report the Nyquist plots of negatively charged carbon electrodes in various ILs at 
different temperatures. The plots shown in Figures 4-6 exhibit common features. The uncompensated resistance $\left(\mathrm{R}_{\mathrm{u}}\right.$, impedance at $\left.100 \mathrm{kHz}\right)$, which is directly related to IL ionic conductivity, is less than $30 \%$ of total electrode impedance at $10 \mathrm{mHz}$. The high frequency semicircle is due to contact resistances and is affected by the quality of cell assembly, which was the same as that of the IL-based AEDLCs (the cell featured the reference electrode placed midway between working and counter electrodes). The mid-frequency electrode impedance is described by a $45^{\circ}$ transmission line $\left(Z_{45^{\circ}}\right)$ that reflects the porous nature of the electrode. This $Z_{45^{\circ}}$ term is related to pore capacitance and charging resistance, the latter depending on carbon electronic resistance and IL ionic conductivity in the pores. At the lowest frequencies the Nyquist plots deviate from the straight line expected for ideal capacitors both because of the porous nature of the electrode and the slow adsorption or rearrangement of IL ions at the electrode surface [10].

Figure 4 shows the impedance plots of DTC electrodes with and without conducting additive in the same $\mathrm{PYR}_{14}$ TFSI IL at $60^{\circ} \mathrm{C}$ and without additive in $\mathrm{PYR}_{1(2 \mathrm{O})} \mathrm{TFSI}$ at $60^{\circ} \mathrm{C}$ and $30^{\circ} \mathrm{C}$ and confirms the findings obtained by the voltammetric study. Indeed, the $\tau$ values, which can be roughly estimated by the frequency at which the fitting lines of $\mathrm{Z}_{45^{\circ}}$ and of the limit capacitance (line almost parallel to $-\mathrm{Z}_{\mathrm{i}}$ axis) cross, are very similar in all the plots._Figure 4a indicates that the presence of conducting additive in the electrode does not modify the real part of $\mathrm{Z}_{45^{\circ}}$, thus suggesting that the transmission line impedance is mainly affected by the ionic conductivity of the IL in the pores. Indeed, as evinced by the plots in Figure $4 \mathrm{~b}$, the real part of $\mathrm{Z}_{45^{\circ}}$ decreases when the temperature rises, i.e. when ionic conductivity increases. However, if only PYR $\mathrm{R}_{1(2 \mathrm{O})}$ TFSI conductivity is taken into account, $\tau$ should follow the response of the real part of $\mathrm{Z}_{45^{\circ}}$. Differently from what expected, the plots in Figure $4 \mathrm{~b}$ show that $\tau$ is almost the same because, as noted above, the increase of temperature in the case of ILs also raises the capacitance response so that the $\mathrm{C}_{\mathrm{dl}}$ increase almost offsets the resistance drop.

The interplay of IL conductivity and carbon capacitance and their effect on $\tau$ is further highlighted by Figure 5, which shows the Nyquist plots of ACT carbon electrodes at $60^{\circ} \mathrm{C}$ in EMITFSI and PYR 14 TFSI. The former IL exhibits $25 \mathrm{mS} \mathrm{cm}^{-1}$ at $60^{\circ} \mathrm{C}$, a 4-fold higher conductivity than the latter's $\left(25 \mathrm{mS} \mathrm{cm}^{-1}\right.$ at $\left.60^{\circ} \mathrm{C}\right)$, and features imidazolium aromatic cations, which are much more polarizable than the pyrrolidinium ones. Hence, while the real part of $\mathrm{Z}_{45^{\circ}}$ is significantly lower in EMITFSI (of $4 \Omega \mathrm{cm}^{2}$ ) than in PYR 14 TFSI (of $7 \Omega \mathrm{cm}^{2}$ ), $\tau$ is almost the same because of the concomitant gain in the capacitive response.

Figures 5 and 6 show that the electrode resistances of the DTC and ACT carbons are mainly determined by the real part of $\mathrm{Z}_{45^{\circ}}$, which is thus the main contributor to the ESR of IL-based AEDLCs assembled with these materials. The real $Z_{45^{\circ}}$ impedance increases with carbon pore depth, so that it is modulated by the porous nature of the electrodes. Indeed, DTC and ACT carbons of almost the same porosity feature comparable impedance response as shown by the corresponding Nyquist plots in $\mathrm{PYR}_{14} \mathrm{TFSI}$ ionic liquid at $60^{\circ} \mathrm{C}$ in Figure 6 . This Figure also has the impedance spectrum of the $\mathrm{C} 3$ electrode, which exhibits a total electrode resistance that is half that of the DTC and ACT carbons for a very low $\mathrm{Z}_{45^{\circ}}$ pore charging resistance resulting from different carbon pore lengths. As shown by the data in Figure 1, while DTC and ACT carbons have PSDs centered at 2.7 $\mathrm{nm}$, the C3 is basically a meso-macroporous carbon with pores of 10-100 nm and, on the basis of geometric considerations and of the pore volume in Table 1, the latter is presumably made of pores much shallower than the former.

\section{Conclusions}

The design of mesoporous carbon electrodes for the development of IL-based AEDLCs of high performance must take into account IL properties. Carbon electrodes should feature a high specific surface area matched to a low pore volume-and short time constant for the double-layer charging-discharging process; the surface chemistry should be tailored to improve carbon wettability by ILs.

The disordered template carbon DTC with pore size distribution centered at $2.7 \mathrm{~nm}$ features a notably high specific capacitance of $140 \mathrm{~F} \mathrm{~g}^{-1}$ enabling the development of a PYR ${ }_{14}$ TFSI-based AEDLC with specific energy and power of $47 \mathrm{Wh} \mathrm{kg}^{-1}$ and $13 \mathrm{~kW} \mathrm{~kg}^{-1}$ (only electrode loading is considered) at $60^{\circ} \mathrm{C}$ with $\mathrm{V}_{\max }$ of $3.9 \mathrm{~V}$. The moderate mesopore volume of DTC limits the IL amount in the electrodes and, hence, in the supercapacitor so that specific energy and power values of $16-18 \mathrm{Wh} \mathrm{kg}^{-1}$ and $4-5 \mathrm{~kW} \mathrm{~kg}^{-1}$ for a complete cell are feasible.

Further improvement in the performance of PYR ${ }_{14}$ TFSI-based AEDLC could be achieved by lowering ESR by proper design of electrode porosity. Indeed, the main contribution to ESR is electrode charging resistance, which in turn is affected by the ionic resistance in the pores. While the electrode charging resistance depends on IL ionic conductivity, it is also modulated by pore length. Hence, pore geometry is a key parameter in carbon design not only because it defines the carbon surface but also because it can differentially "amplify" the effect of IL conductivity on the electrode charging-discharging process.

\section{Acknowledgements}

Work funded by the European Commission in the Sixth Framework Programme, Sub-programme Sustainable Surface Transport, under Contract No. TST4-CT-2005-518307 (Project ILHYPOS "Ionic Liquid-based Hybrid Supercapacitor"). 


\section{List of Symbols}

\section{Latin letters}

AEDLC Asymmetric electric double-layer capacitor

ACX Aero/cryo/xerogel carbons

$\mathrm{C}$

$\mathrm{C}_{\mathrm{c}} \quad$ Capacitance originated by the space charge layer in the carbon

$\mathrm{C}_{\mathrm{IL}} \quad$ Capacitance originated by ion packing in the ionic liquid

$\mathrm{C}_{\mathrm{dl}} \quad$ Electrode double-layer capacitance $/ \mathrm{F} \mathrm{g}^{-1}$ or F cm

$\mathrm{C}_{\mathrm{dl}, \max } \quad$ Maximum value of electrode double-layer capacitance (exhibited at the lowest voltammetric scan rate)/ $\mathrm{F} \mathrm{g}^{-1}$

$\% \mathrm{C}_{\mathrm{dl}} / \mathrm{C}_{\mathrm{dl}}$ max $\quad$ Normalized electrode capacitance / \%

$\mathrm{CV} \quad$ Cyclic voltammetry

DTC Disordered template carbon

EDLC Symmetric electric double-layer capacitor

EMITFSI 1-Ethyl-3-methylimidazolium bis(trifluoromethanesulfonyl)imide

ESW Electrochemical stability window / V

IL Ionic liquid

OTC Ordered template carbon

PSD Pore size distribution

PYR $_{14}$ TFSI N-butyl-N-methyl-pyrrolidinium bis(trifluoromethanesulfonyl)imide

PYR $_{1(201)}$ TFSI N-methoxyethyl-N methylpyrrolidinium bis(trifluoromethanesulfonyl)imide

$\mathrm{R}_{\mathrm{u}}$

$\mathrm{V}_{\text {tot }}$ Uncompensated electrode resistance as evaluated by the impedance at $100 \mathrm{kHz}$

$\mathrm{p} / \mathrm{p}^{\circ}=0.99 / \mathrm{cm}^{3} \mathrm{~g}^{-1}$

$\begin{array}{ll}\mathrm{V}_{>1.5 \mathrm{~mm}} & \begin{array}{l}\text { Specific volume of carbo } \\ \text { isotherm at } 77 \mathrm{~K} / \mathrm{cm}^{3} \mathrm{~g}^{-1}\end{array}\end{array}$

SBA15 silica template

$\mathrm{S}_{>1.5 \mathrm{~nm}} \quad$ Specific surface area of carbon pores wider than $1.5 \mathrm{~nm}$ from DFT analysis of the $\mathrm{N}_{2}$ adsorption isotherm at $77 \mathrm{~K} / \mathrm{m}^{2} \mathrm{~g}^{-1}$

d Carbon pore size from DFT analysis of the $\mathrm{N}_{2}$ adsorption isotherm at $77 \mathrm{~K} / \mathrm{nm}$

$\mathrm{Z}_{45^{\circ}}$ Greek letters

\section{References}

[1] M. Galiński, A. Lewandowski, I. Stępniak, Electrochim. Acta 2006, $51,5567$.

[2] Z.-B. Zhou, H. Matsumoto, K. Tatsumi, Chem. Eur. J. 2006, 12, 2196.

[3] M. Mastragostino, F. Soavi, in Encyclopedia of Electrochemical Power Sources, J. Garche, C. K. Dyer, P. Moseley, Z. Ogumi, D. Rand, B. Scrosati, Editors, Elsevier, New York, In press.

[4] M. Lazzari, F. Soavi, M. Mastragostino, J. Electrochem. Soc. 2009, 156, A661.

[5] C. Arbizzani, M. Biso, D. Cericola, M. Lazzari, F. Soavi, M. Mastragostino, J. Power Sources 2008, 185, 1575.

[6] M. Lazzari, F. Soavi, M. Mastragostino, J. Power Sources 2008, 178, 490.

[7] A. F. Burke, Electrochim. Acta 2007, 53, 1083.

[8] O. Barbieri, M. Hahn, A. Herzog, R. Kötz, Carbon 2005, 43, 1303.

[9] Md. M. Islam, M. T. Alam, T. Okajima, T. Ohsaka, J. Phys. Chem. C 2009, 113, 3386

[10] M. V. Fedorov, A. A. Kornyshev, Electrochim. Acta 2008, 53, 6835

[11] V. Lockett, R. Sedev, J. Ralston, M. Horne, T. Rodopoulos, J. Phys. Chem. C 2008, 112, 7486

[12] M. Lazzari, M. Mastragostino, F. Soavi, Electrochem. Commun. 2007, 9, 1567.

[13 ] J. Huang, B. G. Sumpter, V. Meunier, Chem. Eur. J. 2008, 14, 6614.

[14] A. Lewandowski, M. Galinski, J. Power Sources 2007, 173, 822.

[15] C. Largeot, C. Portet, J. Chmiola, P.L. Taberna, Y. Gogotsi, P. Simon, J. Am. Chem. Soc. 2008, $130,2730$.

[16] C. O. Ania, J. Pernak, F. Stefaniak, E. Raymundo-Piñero, F. Béguin, Carbon 2009, 47, 3158.

[17] E. Frackowiak, Phys. Chem. Chem. Phys. 2007, 9, 1774

[18] A.G. Pandolfo, A. F. Hollenkamp, J. Power Sources 2006, 157, 11.

[19] R. Ryoo, S.H. Joo, M. Kruk, M. Jaroniec, Adv. Mater. 2001, 13, 677

[20] A.B. Fuertes, Microp. Mesop. Mater. 2004, 67, 273.

[21] K. Xia, Q. Gao, J. Jiang, J. Hu, Carbon 2008, 46, 1718.

[22] S.H. Joo, Electrochim. Acta 2006, 52, 1618.

[23] T. Morishita, Y. Soneda, T. Tsumura, M. Inagaki, Carbon 2006, 44, 2360. 
[24] T. Morishita, K. Ishihara, M. Kato, M. Inagaki, Carbon 2007, 45, 209.

[25] M. Inagaki, M. Kato, T. Morishita, K. Morita, K. Mizuuchi, Carbon 2007, 45, 1121.

[26] R. Kötz, M. Carlen, Electrochim. Acta, 2000, 45, 2483.

\section{Figure Captions}

Fig. 1. DFT specific incremental pore volume vs. pore size of the carbons OTC, DTC, ACT and C3.

Fig. 2. Specific capacitance $\left(\mathrm{C}_{\mathrm{dl}}\right)$ from CVs at $20 \mathrm{mV} \mathrm{s}^{-1}$ and $60^{\circ} \mathrm{C}$ in PYR ${ }_{14} \mathrm{TFSI}$ and in the potential range $2.6 /-0.2 \mathrm{~V} \mathrm{vs}$. Fc/Fc $\mathrm{Fc}^{+}$of $\mathrm{OTC}$ (open triangle), DTC (open diamond), ACX (solid square), AC (solid circle), and ACT (open circle) carbons vs. $S_{>1.5 \mathrm{~nm}}$.

Fig. 3. Voltage profile of the in-PYR ${ }_{14}$ TFSI-based AEDLC with DTC electrodes upon the $1100^{\text {th }}$ galvanostatic charge-discharge cycle at $20 \mathrm{~mA} \mathrm{~cm}^{-2}$ and $60^{\circ} \mathrm{C}$

Fig. 4. Nyquist plots of DTC electrodes with almost the same carbon content a) with and without carbon conducting additive at $60^{\circ} \mathrm{C}$; b) without carbon conducting additive in $\mathrm{PYR}_{1(2 \mathrm{O})} \mathrm{TFSI}$ at $30^{\circ} \mathrm{C}$ and $60^{\circ} \mathrm{C}$.

Fig. 5. Nyquist plots of ACT carbon electrodes at $60^{\circ} \mathrm{C}$ in EMITFSI and PYR ${ }_{14} \mathrm{TFSI}$.

Fig. 6. Nyquist plots of DTC, ACT and $\mathrm{C} 3$ electrodes in PYR ${ }_{14} \mathrm{TFSI}$ at $60^{\circ} \mathrm{C}$.

\section{Tables}

Table 1 DFT specific pore volume $\left(\mathrm{V}_{>1.5 \mathrm{~nm}}\right)$ and specific surface area $\left(\mathrm{S}_{>1.5 \mathrm{~nm}}\right)$ from pores with size in the 1.5 $\mathrm{nm}-200 \mathrm{~nm}$ range, and main pore size (d) of the carbons investigated for IL-based AEDLCs.

\begin{tabular}{|c|c|c|c|c|}
\hline Carbon type & Code & $\mathrm{V}_{>1.5 \mathrm{~nm}} / \mathrm{cm}^{3} \mathrm{~g}^{-1}$ & $\mathrm{~S}_{>1.5 \mathrm{~nm}} / \mathrm{m}^{2} \mathrm{~g}^{-1}$ & $\mathrm{~d} / \mathbf{n m}$ \\
\hline Ordered template & OTC & 0.59 & 225 & 5.7 \\
\hline Disordered template & DTC & 0.70 & 1018 & 2.7 \\
\hline $\begin{array}{l}\text { Aero/cryo/xerogel } \\
\text { (ACX) }[6,12]\end{array}$ & $\begin{array}{c}\text { C2 } \\
\text { X1 } \\
\text { X1a } \\
\text { X2a } \\
\text { X3a } \\
\text { A1a } \\
\text { C3 }\end{array}$ & $\begin{array}{l}0.23 \\
0.66 \\
0.52 \\
0.99 \\
1.32 \\
0.62 \\
2.93\end{array}$ & $\begin{array}{l}134 \\
216 \\
372 \\
412 \\
564 \\
610 \\
360\end{array}$ & $\begin{array}{c}9 \\
15 \\
6 \\
14 \\
15 \\
6 \\
10-100\end{array}$ \\
\hline $\begin{array}{l}\text { Activated carbon } \\
{[12]}\end{array}$ & $\begin{array}{l}\mathrm{AC} \\
\mathrm{ACT}\end{array}$ & $\begin{array}{l}0.84 \\
0.84\end{array}$ & $\begin{array}{l}1020 \\
972\end{array}$ & $\begin{array}{l}2.7 \\
2.7\end{array}$ \\
\hline
\end{tabular}

Table $2 \mathrm{~V}_{\max }, \mathrm{C}$, ESR, Q, $\eta$, maximum specific energy $\left(\mathrm{E}_{\max }={ }^{3} /{ }_{8} \mathrm{C} \mathrm{V}_{\max }{ }^{2}\right.$, for a discharge down to $\left.50 \% \mathrm{~V}_{\max }\right)$ and maximum specific power $\left(\mathrm{P}_{\max }=\mathrm{V}_{\max }{ }^{2} /\left(4 \mathrm{ESRW}_{\text {comp }}\right)\right)$ at the $1100^{\mathrm{th}}$ galvanostatic charge-discharge cycle at $20 \mathrm{~mA} \mathrm{~cm}^{-2}$ and $60^{\circ} \mathrm{C}$ of the PYR $\mathrm{PY}_{14}$ TFSI-based AEDLC assembled with DTC carbon electrodes with $\mathrm{R}_{+/-}=1.3$ and $\mathrm{w}_{\text {comp }}=20 \mathrm{mg} \mathrm{cm}^{-2}$. The gravimetric performance are given referring to $\mathrm{w}_{\text {comp. }}$.

\begin{tabular}{|c|c|c|c|c|c|c|}
\hline $\mathbf{V}_{\max } / \mathbf{V}$ & $\mathrm{C} / \mathrm{F} \mathrm{g}_{\mathrm{comp}}{ }^{-1}$ & $\mathrm{ESR} / \Omega \mathrm{cm}^{2}$ & $\mathrm{Q} / \mathrm{mAh} \mathrm{g} \mathrm{comp}^{-1}$ & $\eta \%$ & 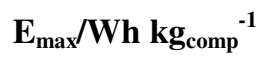 & $P_{\max } / \mathbf{k W ~ k g}$ comp $^{-1}$ \\
\hline 3.9 & 30 & 14 & 23 & 99.4 & 47 & 13 \\
\hline
\end{tabular}


Table 3 Normalized capacitance at different voltammetric scan rates and temperatures of the DTC electrodes (with and without SuperP conducting additive) in PYR ${ }_{14}$ TFSI and PYR $\mathrm{R}_{1(2 \mathrm{O})}$ TFSI in the electrode potential ranges $-2.2 /-0.2 \mathrm{~V}$ and $-2.1 /-0.2 \mathrm{~V}$ vs. $\mathrm{Fc} / \mathrm{Fc}^{+}$, respectively.

\begin{tabular}{|c|c|c|c|c|}
\hline \multirow{3}{*}{$\mathbf{T} /{ }^{\circ} \mathbf{C}$} & \multirow{3}{*}{ scan rate $/ \mathrm{mV} \mathrm{s}^{-1}$} & \multicolumn{3}{|c|}{$\% \mathrm{C}_{\mathrm{dl}} / \mathbf{C}_{\mathrm{dl}, \max }$} \\
\hline & & \multicolumn{2}{|c|}{ PYR $_{14}$ TFSI } & PYR $_{1(201)}$ TFSI \\
\hline & & 0\% Super P & 5\% SuperP & 0\% Super P \\
\hline \multirow{6}{*}{60} & 5 & 100 & 100 & 100 \\
\hline & 10 & 90 & 90 & 90 \\
\hline & 20 & 75 & 85 & 75 \\
\hline & 30 & 65 & 75 & 70 \\
\hline & 40 & 55 & 70 & 65 \\
\hline & 50 & 50 & 60 & 50 \\
\hline \multirow{6}{*}{30} & 5 & 100 & 100 & 100 \\
\hline & 10 & 90 & 95 & 90 \\
\hline & 20 & 80 & 80 & 75 \\
\hline & 30 & 60 & 70 & 70 \\
\hline & 40 & 50 & 60 & 65 \\
\hline & 50 & 45 & 55 & 50 \\
\hline
\end{tabular}




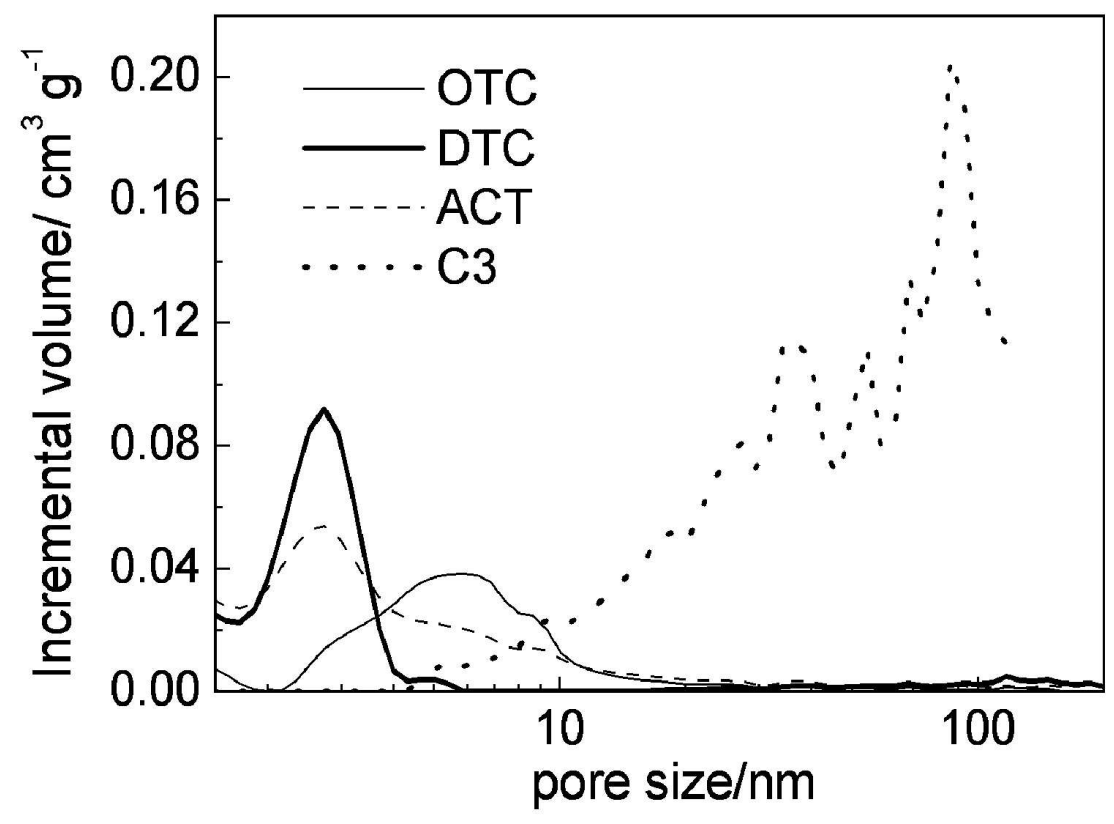

Figure 1. DFT specific incremental pore volume vs. pore size of the carbons OTC, DTC, ACT and C3. $270 \times 195 \mathrm{~mm}(500 \times 500 \mathrm{DPI})$ 


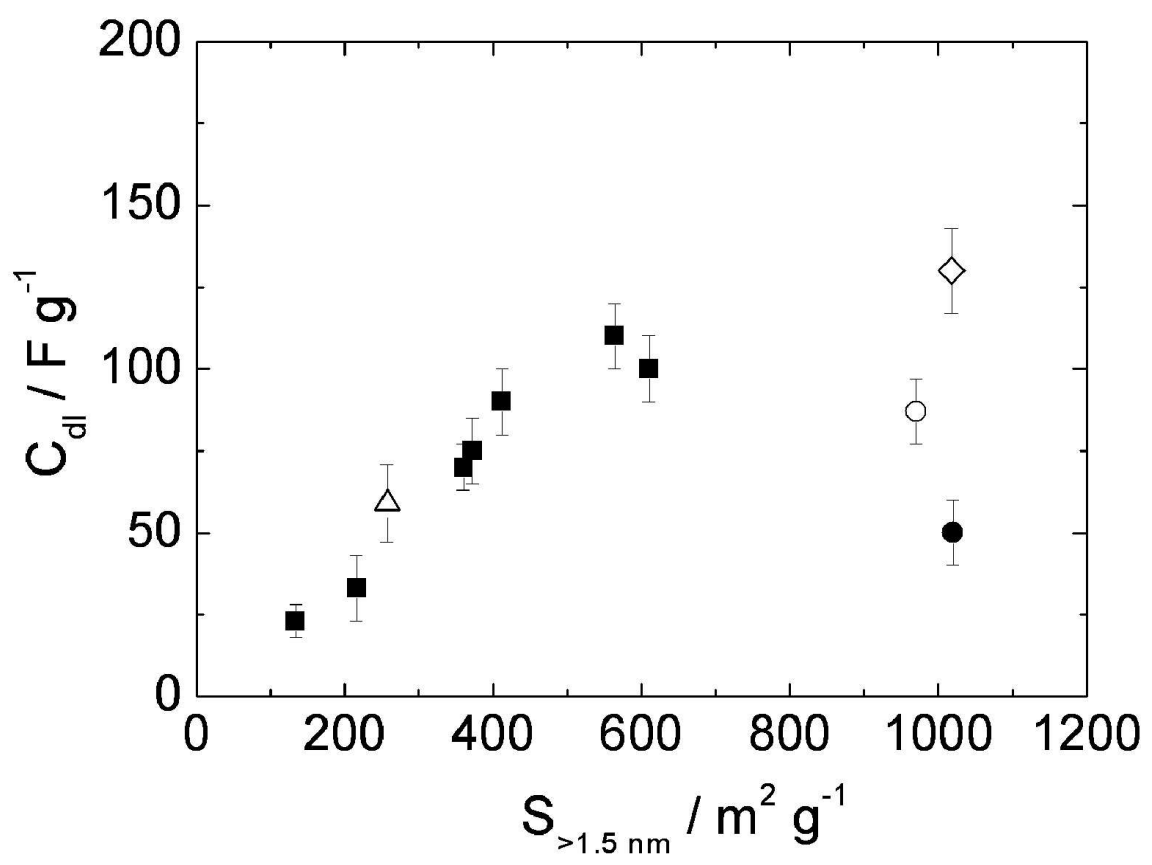

Figure 2. Specific capacitance $\left(\mathrm{C}_{\mathrm{dl}}\right)$ from CVs at $20 \mathrm{mV} \mathrm{s}^{-1}$ and $60^{\circ} \mathrm{C}$ in $\mathrm{PYR}_{14} \mathrm{TFSI}$ and in the potential range $-2.6 /-0.2 \mathrm{~V}$ vs. FC/FC ${ }^{+}$of OTC (open triangle), DTC (open diamond), ACX (solid square), AC (solid circle), and ACT (open circle) carbons vs. $S_{>1.5 \mathrm{~nm}}$. $270 \times 188 \mathrm{~mm}(500 \times 500 \mathrm{DPI})$ 
Figure 3. Voltage profile of the PYR 14 TFSI-based AEDLC with DTC electrodes upon the $1100^{\text {th }}$ galvanostatic charge-discharge cycle at $20 \mathrm{~mA} \mathrm{~cm}^{-2}$ and $60^{\circ} \mathrm{C}$ $270 \times 195 \mathrm{~mm}(500 \times 500 \mathrm{DPI})$ 
Figure 4. Nyquist plots of DTC electrodes with almost the same carbon content a) with and without carbon conducting additive at $60^{\circ} \mathrm{C}$; b) without carbon conducting additive in $\mathrm{PYR}_{1(201)}$ TFSI at $30^{\circ} \mathrm{C}$ and $60^{\circ} \mathrm{C}$

$140 \times 203 \mathrm{~mm}(500 \times 500 \mathrm{DPI})$ 


1
2
3
4
5
6
7
8
9
10
11
12
13
14
15
16
17
18
19
20
21
22
23
24
25
26
27
28
29
30
31
32
33
34
35
36
37
38
39
40
41
42
43
40
45
49
50
51
52
53
55
50

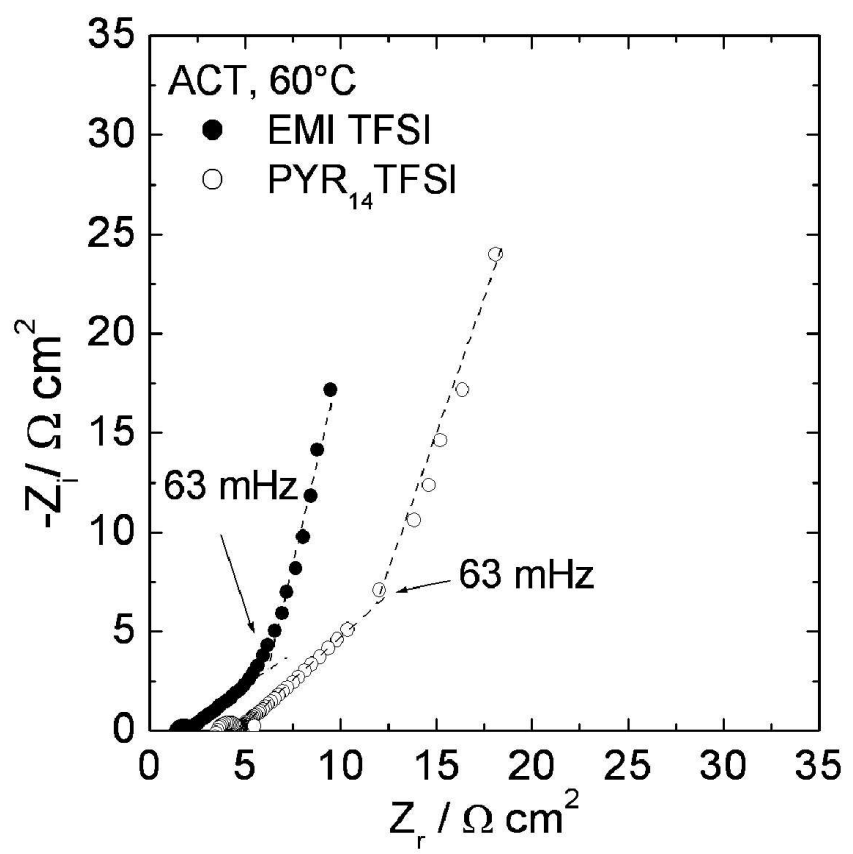

Figure 5. Nyquist plots of ACT carbon electrodes at $60^{\circ} \mathrm{C}$ in EMITFSI and PYR ${ }_{14}$ TFSI. $270 \times 195 \mathrm{~mm}(500 \times 500 \mathrm{DPI})$ 


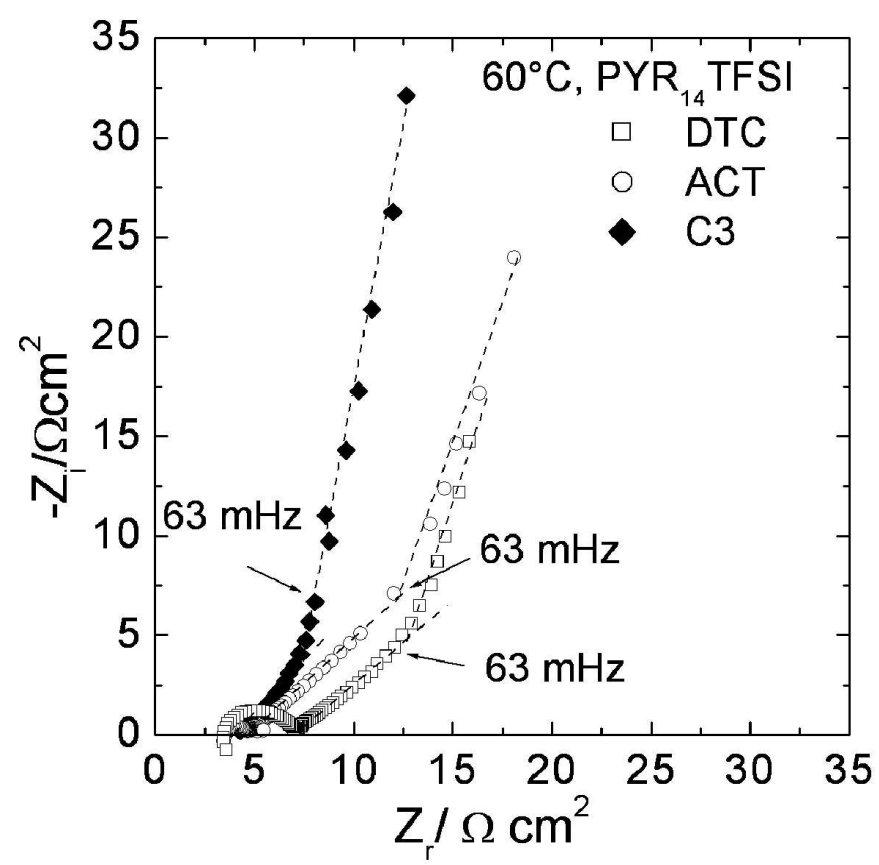

Figure 6. Nyquist plots of DTC, ACT and C3 electrodes in PYR ${ }_{14} T F S I$ at $60^{\circ} \mathrm{C}$. $270 \times 195 \mathrm{~mm}(500 \times 500$ DPI $)$ 